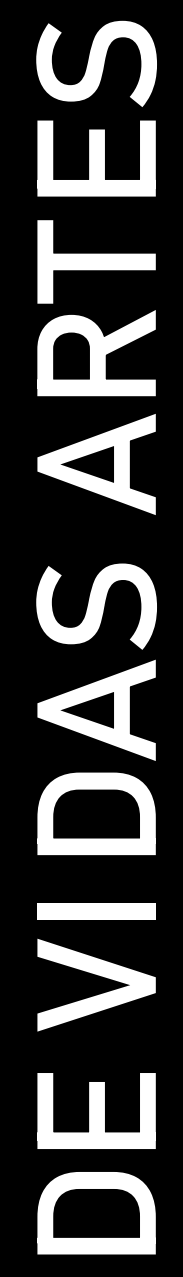

PAULA GUERRA E LÍGIA DABUL (EDS.) 


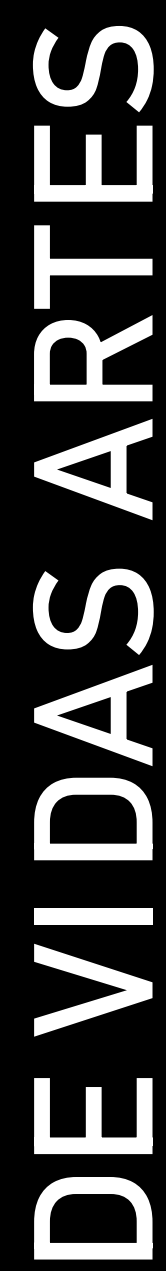

\section{PAULA GUERRA E LÍGIA DABUL (EDS.)}

Design por Irandina Afonso

Ilustração da Capa por Lua Celina

Publicado em Setembro 2019

Universidade do Porto. Faculdade de Letras

[University of Porto. Faculty of Arts and Humanities]

Porto, Portugal

ISBN 978-989-8969-18-7

Suporte: Eletrónico - Formato: PDF / PDF/A 


\title{
III.5. O artivismo de Hélio Rôla: Do pincel ao pixel
}

\section{III.5. Hélio Rôla's artivism: From brush to pixel}

\section{Flávia Fernanda Fernandes}

\section{Resumo}

O presente capítulo tem como propósito realizar uma reflexão sobre artivismo a partir da obra e do percurso do artista visual cearense Hélio Rôla. Neste horizonte, o capítulo apresenta algumas obras do artista para subsidiar o tratamento da produção artística contemporânea no âmbito do artivismo. Da pintura mural na década de 70 a sua atual presença nas redes sociais, Hélio Rôla transita entre o pincel e o pixel, com o intuito de intervir no tom do cotidiano, produzindo além de obras, testemunhos de seu tempo. Desse modo, o que se pode aferir é que o artivismo tem como pressuposto um diálogo intenso com o seu contexto social, sendo de certo modo situado e situacional, onde a arte não se apresenta apenas como um aspecto formal, mas também como função que interfere e possibilita a criação de novas narrativas acerca da realidade social.

Palavras-chave: artivismo, Hélio Rôla, sociologia da arte.

\begin{abstract}
The purpose of this chapter is to conduct a discussion about artivism based on the work and the course of visual artist Hélio Rôla from Ceará. On this horizon, the chapter presents some works by the artist to subsidize a reflection on contemporary artistic production in the ambit of artivism. From mural painting in the 70's to its current presence in social networks, Hélio Rôla transits between the brush and the pixel, with the intention of intervening in the tone of daily life, producing besides works, testimonies of his time. Thus, what can be verified is that artivism presupposes an intense dialogue with its social context, being in a certain way situated and situational, where art presents itself not only as a formal aspect, but also as a function that interferes and enables the creation of new narratives about social reality.
\end{abstract}

Key words: artivism, Hélio Rôla, sociology of art.

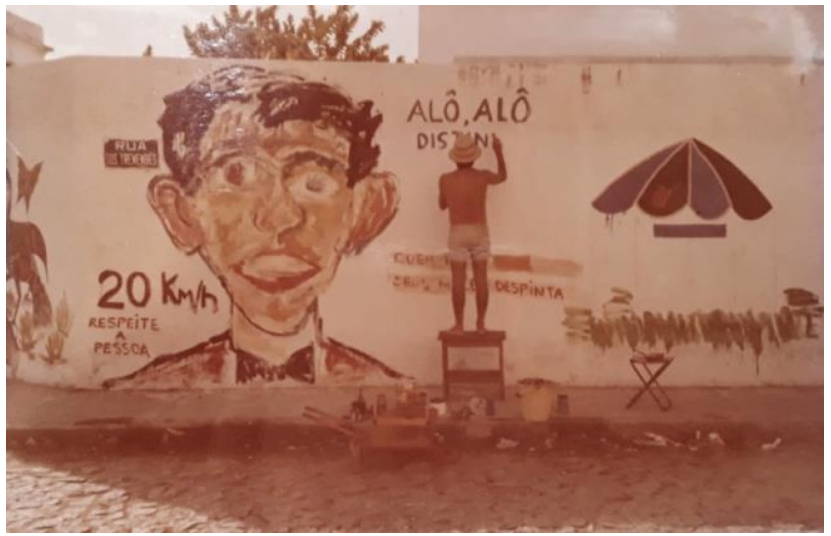

Figura III.5.1: Hélio Rôla realizando pintura mural na Praia de Iracema, 1977 Fonte: Acervo do artista. 
Fortaleza, $1977^{171}$. A fotografia acima registra o artista visual Hélio Rôla ${ }^{172}$ pintando sobre um muro no bairro Praia de Iracema. Nela é possível perceber inscrições como "20 km/h”, "Respeite a Pessoa", “Alô, Alô, Distinto”, “Quem pinta seus males despinta". Em cada uma dessas sentenças, prevalece o sentido de uma exortação direcionada ao público. As frases evidenciam a questão da velocidade estabelecida para a circulação de veículos nas ruas do bairro residencial, invadido pelas demandas boêmias e culturais da capital que se abria para o turismo naquele momento. Pede respeito às pessoas. $E$ assume: "quem pinta os males, despinta", expressão de "alívio" em manifestar sua indignação por meio da arte mural pública.

O cenário anterior à realização desse mural era aquele de uma parte da rua tomada por lixo acumulado. Como parte da intervenção e para sensibilizar a vizinhança, o artista e sua família limparam a rua e ele pintou o muro. Com esta proposta de "arte pública", o artista buscou trazer de volta a dimensão do belo e do cuidado, por meio da relação entre artista, contexto e públicos:

\footnotetext{
Essa foi uma intervenção na Praia de Iracema. Era uma ideia de arte pública. Os passantes que não vão ao museu e galerias, poderiam ver e apreciar a arte que estava lá. Era uma maneira também de intervir na paisagem. Os pintores do Pirambu173 participaram de alguns murais. Alguns vizinhos e amigos artistas se interessaram e passaram a contribuir também.
}

A arte mural do artista na Praia de Iracema tinha objetivos claros: assumir uma atitude provocativa em relação aos elementos do seu contexto de vida, com destaque para a temática socioambiental, tônica recorrente no percurso e discurso de Hélio Rôla:

Era um modo de chamar a atenção e sensibilizar a população para
intervir na limpeza, no combate ao lixão que se formava nesse
local. Usava a arte para sensibilizar e embelezar, de certa forma,
o lugar, para evitar o acúmulo de lixo. Definia um lugar com minha
família e íamos pintar sem muita organização. Primeiro limpava o
lugar, retirava o lixo, caiava o muro e fazia a pintura. No começo,
a gente pintava em cima do lixo mesmo, que era muito. Mas, com a
diminuição, conseguimos limpar. Até acabar.

171 Este capítulo resulta do desenvolvimento do doutorado da autora intitulado "Traços, Trajetos e Travessias: uma cartografia das artes visuais em Fortaleza" no Programa de Pós-Graduação em Sociologia da Universidade Estadual do Ceará sob orientação científica da Professora Doutora Kadma Marques Rodrigues.

172 Hélio Rôla, nascido em 1936, é artista visual cearense e reside em Fortaleza. Pintor, desenhista, escultor e gravador, Hélio Rôla se define como artista múltiplo e o artivismo é uma tônica presente em sua obra.

${ }^{173}$ Também conhecida como "Escola do Pirambu", era formada por um grupo de artistas que atuavam junto ao artista naiffChico da Silva. 
Naquele momento, este tipo de intervenção ainda não recebia a denominação artivismo, embora o contexto político das décadas de 1960 e 1970 tenha propiciado manifestações artísticas como happenings, performances e a emergência de termos como "arte protesto" e "arte ativista", ocupando o espaço de diálogo entre os campos das artes e das ciências sociais. O desafio que se impõe à definição deste tipo de produção artística refere-se ao fato de que ela se situa em meio a um dilema: por um lado, tais produções não podem ser analisadas somente a partir de seu teor político; tampouco, devem ser pensadas exclusivamente como forma artística. Nessa perspectiva, Bourdieu (1995: 86), em diálogo com Hans Haacke, defendia que "as formas falam e o tema se inscreve nas formas", de modo que as obras de arte se configuram como "marcos ideológicos", e na condição de sinal de poder e de capital simbólico, as obras de arte são portadoras de um papel político em si.

Conforme elucida Longoni (2009), a partir do momento em que esses processos ultrapassam as convenções e limites de ambos os campos, faz-se necessário elaborar um termo que contemple a "novidade ${ }^{174 "}$ representada pela convergência entre arte e política. Desse modo, o termo artivismo parece elucidativo, evidenciando sobreposições e intersecções que geram um novo consenso no tocante ao modo específico de fazer política no campo da arte.

Assim, desde a década de 1990, o termo artivismo vem sendo incorporado de forma paulatina e sistemática, tanto no universo das ciências sociais quanto naquele das artes. A demanda por analisar e classificar expressões artísticas com teor crítico-político como manifestações de protesto e reivindicação, seja de autoria individual ou coletiva, cria as condições para que este conceito se estabeleça. Ainda que de modo instável e não sem contraditórios, ele ganhou espaço como categoria para pesquisas no campo da sociologia da arte, sobretudo no processo de transição paradigmática entre a arte moderna e a arte contemporânea.

Nessa perspectiva, tornou-se inoperante a pretensão de construir um 'olhar puro' e de separar a arte da vida cotidiana. A ideia de "arte pela arte" perdeu força e lugar nos debates sobre o fazer artístico contemporâneo. Ao

\footnotetext{
${ }^{174}$ Ao tratar o artivismo como novidade, Bourdieu (1995) auxilia na compreensão de que a liberdade dos artistas a partir da autonomização no campo artístico, avançou a nível formal, mas não em termos de função e política. Cabe lembrar que apesar do termo artivismo ser relativamente novo, diversos movimentos artísticos como o surrealismo, construtivismo, dadaísmo tinham objetivos explicitamente políticos.
} 
contrário, uma parte da produção atual tem se preocupado em desfazer essas barreiras a partir de projetos de arte colaborativa que costumam centrar suas ações na experiência dos participantes, questionando a ideia de autoria. Nessa esteira, o artivismo aparece com mais intensidade, como uma arte com propósito, uma "arte atuante" ou como expressão de uma "ética estética", conforme Mourão (2015: 63): uma arte de natureza questionadora do status quo, que se coloca a serviço da sociedade, "em prol da conquista de um espaço de liberdade, de expressão político-artística, para a crítica dissonante em relação ao injusto dominante". O artivismo tem se firmado como uma vanguarda mais radical e interdisciplinar no campo artístico, conforme complementa Raposo:

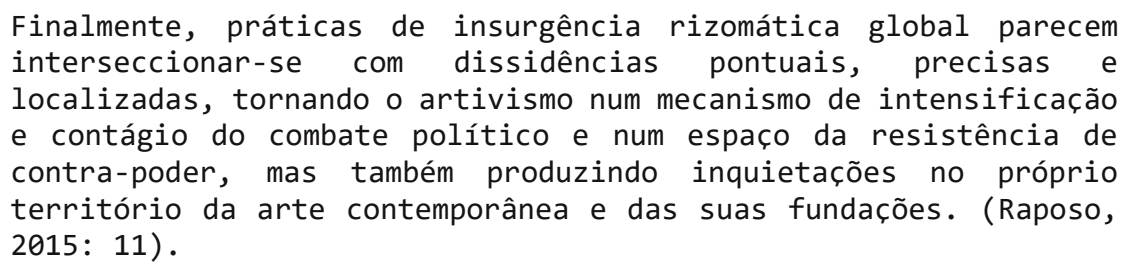

A arte ativista é considerada um gênero de arte pública, sobretudo pelo fato dos trabalhos dessa natureza estarem em íntima conexão com o contexto físico e social onde o artista está inserido, bem como, pela distinta relação que estabelece com o público, conforme explica Suzanne Lacy (1994: 8):

\begin{abstract}
Na busca de se tornar catalisadores de mudança, os artistas se reposicionam como cidadãos-ativistas. Diametralmente opostas às práticas estéticas do artista isolado, a construção de consensos inevitavelmente implica o desenvolvimento conjunto de habilidades não comumente associadas à criação de arte. Para se posicionar em relação à agenda pública, o artista deve atuar em colaboração com as pessoas e com uma compreensão dos sistemas e instituições sociais. Estratégias inteiramente novas devem ser aprendidas: como colaborar, como desenvolver públicos de múltiplas camadas e específicos, como cruzar com outras disciplinas, como escolher sites que ressoam com significado público, e como esclarecer o simbolismo visual e processual para pessoas que são possuem uma educação voltada para a Arte. Em outras palavras, os artistasativistas questionam a primazia da separação como uma postura artística e realizam a produção consensual de significado com o público175.
\end{abstract}

É válido salientar que o artivismo não se define pela simples oposição a partir de uma contestação, mas em um processo que culmina com uma arte essencialmente crítica, que busca sensibilizar para a reflexão. É uma ação

\footnotetext{
${ }^{175}$ No original: In seeking to become catalysts for change, artists reposition themselves as citizen-activists. Diametrically opposed to the aesthetic practices of the isolated artist, consensus building inevitably entails developing a set of skills not commonly associated with art making. To take a position with respect to the public agenda, the artist must act in collaboration with people, and with an understanding of social systems and institutions. Entirely new strategies must be learned: how to collaborate, how to develop multilayered and specific audiences, how to cross over with other disciplines, how to choose sites that resonate with public meaning, and how to clarify visual and process symbolism for people who are not educated in art. In other words, artist-activists question the primacy of separation as an artistic stance and undertake the consensual production of meaning with the public.
} 
artística com o propósito de abrir espaços para questionamentos, críticas e, sobretudo, para o diálogo e mudança de posicionamentos no campo social. Nesse sentido, não necessariamente esses objetivos se configurarão em ações pragmáticas, embora sejam essas as inquietações que motivam um artista ativista à ação. Para Lippard (1984), a arte ativista não é um tipo de arte, mas uma proposta de abordagem conceitual, de característica processual, uma possibilidade que o artista explora para se conectar com a sua experiência no mundo. Para Raposo (2015: 13), o termo artivismo configura-se ao mesmo tempo como "causa e reivindicação social e simultaneamente como ruptura artística", sobretudo pelo surgimento de novos cenários e sugestão de modos alternativos de consumo e fruição, como também pelas peculiaridades no tocante à participação e criação artística. Uma característica fundamental do artivismo consiste na capacidade de questionar criticamente os sistemas de representação vigentes, para além dos parâmetros definidos pelos poderes políticos, sociais, culturais e econômicos.

Desse modo, Raposo (2016) reforça que o uso do conceito de artivismo adequa-se à compreensão dos sentimentos de insatisfação que dão base a protestos sociais, ressaltando que a partir de intervenções artivistas surgem espaços e possibilidades de resistência à repressão, mas elas também trazem à visibilidade o invisível, ao mesmo tempo em que oferecem versões alternativas às narrativas oficiais, sobretudo no tocante à arte e à história.

Guerra (2015) avança ainda mais ao tratar de artivismo, de vez que a autora afirma que não estamos diante apenas de uma categoria ou modo de produzir arte, mas perante manifestações que buscam para além de denunciar, intervir e reconfigurar o espaço social de modo duradouro. Por isso, a grande diversidade temática subsidia o trabalho artístico sobre objetos, os quais convertem problemas sociais ou questões aparentemente banais em problemas plásticos. Assim, na Praia de Iracema, grande parte dos murais dessa época tinha temáticas circenses devido a sua maleabilidade plástica e por representar um universo social instigante, cuja complexidade pode ser descortinada por diversos enfoques. De uma prática que acontecia entre familiares, animada por Hélio Rôla, a pinturas murais que passaram a contar com a participação de vizinhos, amigos e outros artistas da cidade, um 
movimento de arte pública em Fortaleza foi ganhando adeptos e configuração mais organizada.

Eu e a Efi estávamos trabalhando com o circo, no fim da década de 70. O circo era parte da pesquisa de mestrado da minha esposa, e acabou se tornando uma inspiração, um motivo também. Fizemos uma série de filmes super 8 na época. Mas, nesse momento, estava na Praia de Iracema e começamos a fazer as pinturas murais. Depois foram se juntando à nossa família os pintores do Pirambu e vizinhos que se interessaram em participar. Posteriormente, veio o Grupo Aranha.

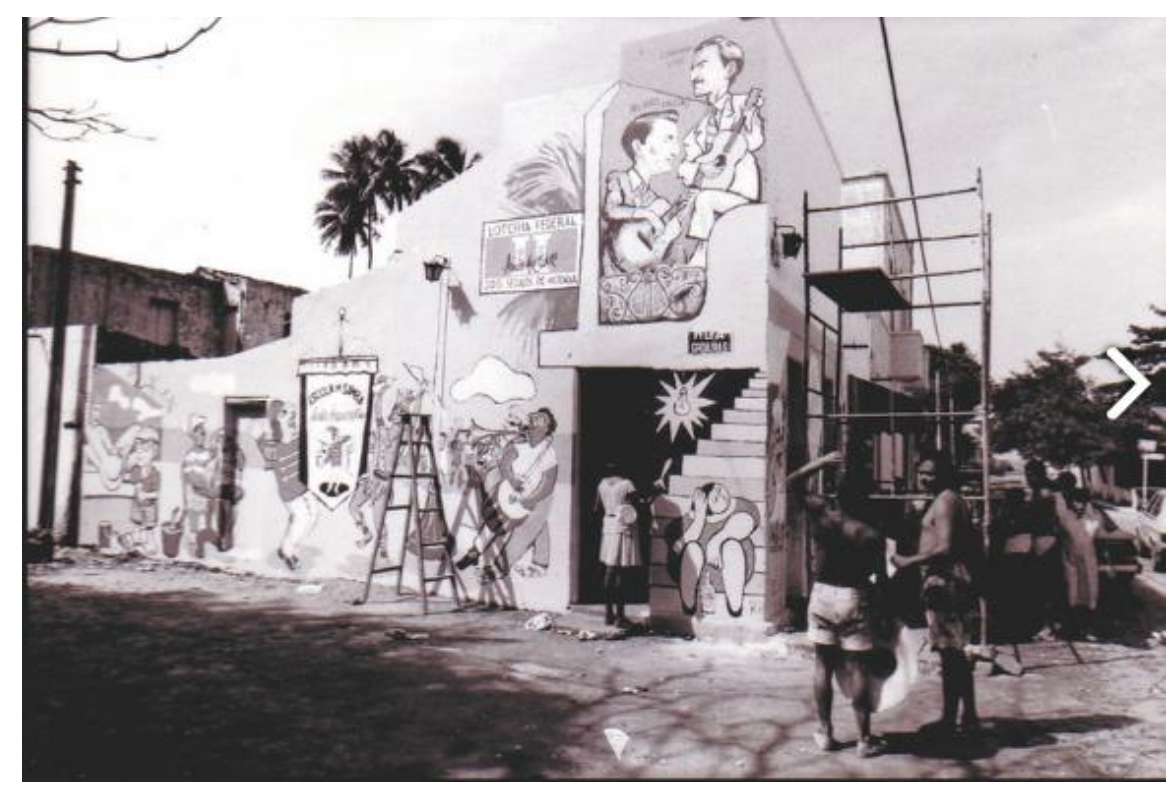

Figura III.5.2: Grupo Aranha realizando intervenção na Praia de Iracema, 1987

Fonte: Acervo de Hélio Rôla.

A imagem acima revela uma ação coletiva realizada pelo Grupo Aranha, surgido em 1987. Assim, é possível afirmar que as pinturas-murais realizadas por Hélio Rôla, na Praia de Iracema, emergiram da espontaneidade de uma atividade intervencionista que reunia familiares e vizinhos, e passou à ação coletiva de artistas cujo percurso formativo provocou mútua atratividade e reconfiguração do campo artístico na capital cearense. Abaixo, o artista comenta o processo.

Já tinha visto grafites em Nova Iorque. Na Praia de Iracema, a pintura mural surgiu primeiro do meu propósito em usar a arte nos muros para chamar a atenção para o lixo na vizinhança. Depois de certo tempo, se explicitou o protesto à poluição sonora na Praia de Iracema. Eu já pintava muros na Praia de Iracema. O Sérgio Pinheiro, que estudou na França com um especialista em arte pública, ao retornar para o Brasil sugeriu a ideia de formar um grupo de pintura mural, e assim se deu o Grupo Aranha. Com a criação do Grupo Aranha, pintamos o mural SOS IRACEMA, usando as habilidades artísticas para fazer um protesto. Disso a coisa se seguiu para outras pinturas, que aconteciam de forma coletiva. 
Foi um encontro de artistas, realizando uma arte colaborativa. Não havia ainda um contexto de ação coletiva entre artistas aqui em Fortaleza, além de ser uma arte pública.

Hélio Rôla compreende este como um momento significativo de emergência de novos valores que passam a interferir nos contornos desse campo de atuação. Naquele contexto, a ação coletiva e o anonimato das individualidades que se colocavam ao abrigo da assinatura "Grupo Aranha", disputavam lugar com trajetórias artísticas construídas sob o signo da singularidade do artista criador. $O$ artista relembra com detalhes os processos artísticos vivenciados de modo colaborativo, entre aqueles que compunham então o Grupo Aranha. De forma experimental, juntos, eles foram desenvolvendo um modo de criar coletivamente.

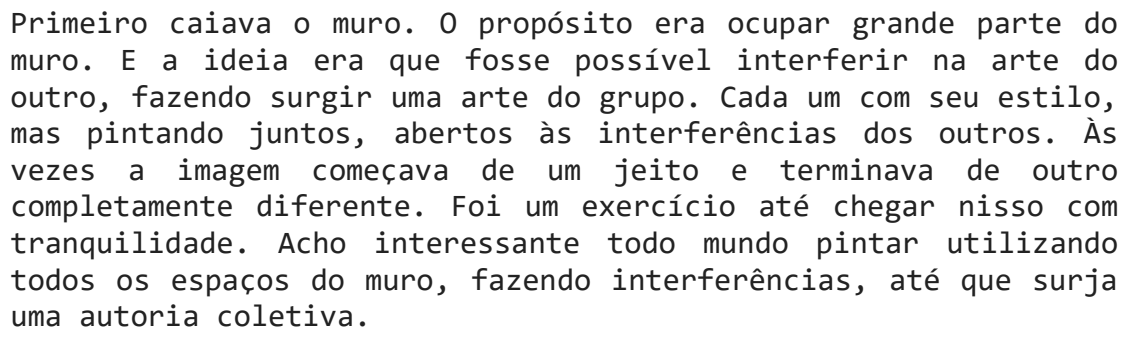

Ao longo do período de existência do Grupo Aranha, de 1987 a 1991, o coletivo artístico realizou uma série de pinturas e intervenções em Fortaleza. $\mathrm{Na}$ época, sendo a autoria coletiva um fenômeno absolutamente novo na capital cearense, seu exercício exigia ajustes complexos em termos de interação criativa. Apesar do desejo daqueles artistas que defendiam a realização de uma arte de base colaborativa, o processo criativo não se dava sem que houvesse conflitos entre esses agentes, marcados pelo imaginário da arte moderna. O artista e pesquisador Herbert Rolim comenta as intervenções do Grupo Aranha, ressaltando sua relevância para a história das Artes Visuais do Ceará:

A primeira ação de ressonância pública, assinada pelo Grupo Aranha, foi engendrada por motivações políticas, em 1987, quando um painel de $150 \mathrm{~m}$ de comprimento, intitulado Constituinte, despontou no muro da Companhia de Eletricidade do Ceará na Avenida Leste Oeste, chamando atenção da cidade. [...] Outra "brigada de pintura", esta de ordem ecológica, bateu de frente com a poluição sonora na Praia de Iracema, que, a partir da segunda metade da década dos anos 80, começou a sofrer invasão de empresários da noite, ao mesmo tempo em que a classe burguesa residente preferiu evadir para Aldeota, permanecendo no bairro aqueles moradores mais resistentes. Desse quadro, em 1989, figurou o mural "SOS Praia de Iracema", estruturado pelo Grupo Aranha, aberto a todos os artistas (e não artistas) que quisessem participar com a finalidade de mobilizar a comunidade, recolher assinaturas de protesto, chamar atenção da mídia e sensibilizar a classe política. Jornal Diário do Nordeste, Caderno 3, 08/03/2015. 
Após o fim do Grupo Aranha, e instigado pela recente experiência de pintura sobre os muros da cidade, Hélio Rôla passou a pintar telas em grande formato. Assim, conservando uma arte-denúncia, com teor de protesto, o artista dedicou-se à produção de uma série de telas, integradas posteriormente como coleção intitulada "Iracema by Night". Não só no âmbito desta, mas de toda a sua carreira, a tela "Pesadelo Cult" talvez seja uma das mais relevantes. Hélio Rôla comenta a seguir:

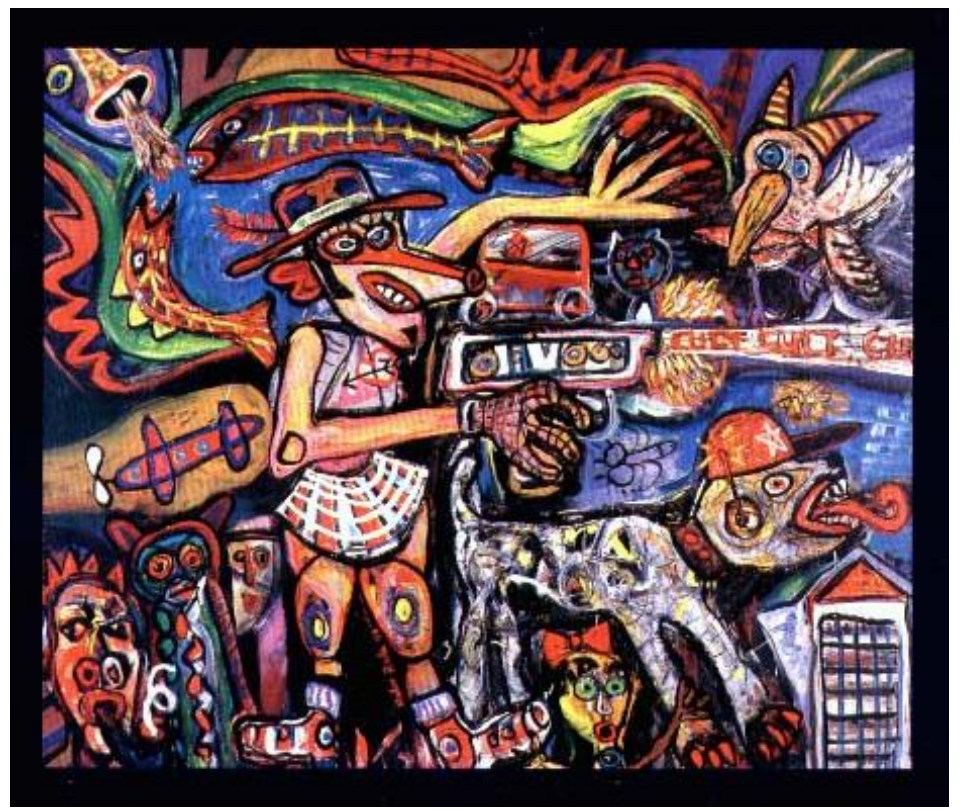

Figura III.5.3: Pesadelo Cult, Óleo sobre tela, 1996

Fonte: Acervo do artista.

\begin{abstract}
Ela remete o observador a uma sobrecarga, não é uma pintura bonita. Mas dentro desse feio tem o bem feito. Uma sobrecarga de imagens que reflete o que acontecia na Praia de Iracema: Poluição sonora, carros, prostituição. É uma arte-denúncia. Alguém com uma metralhadora, é o avanço da cultura de massa. Cult Cult Cult são os tiros. Um ambiente perturbador. É o que vivi na Praia de Iracema. Foi como eu traduzi o impacto que vivi na Praia de Iracema, imagens de horror e sobrecarga. Uma poesia brutal que externava a perturbação que eu vivenciava. Um visual que se posiciona.
\end{abstract}

As obras dessa série atuam como forma de expressão do mal-estar que caracterizava o momento de vida subjetiva do artista, mas também representam um engajamento público na resolução de problemas enfrentados pela coletividade de moradores do bairro Praia de Iracema. Munido de pincéis e tintas, ele filtrava em termos formais os elementos de um cotidiano no qual se cruzavam diversos problemas sociais. Ironicamente, mais de uma década depois, essa pintura, de caráter crítico em relação à atuação do poder público como agente mediador do processo de intensificação do turismo no bairro, foi 
adquirida pelo Prêmio Aquisição do Governo do Estado do Ceará, para exposição no Palácio da Abolição, sede governamental. Hélio Rôla avalia este fato como importante processo de inversão simbólica provocada pela arte.

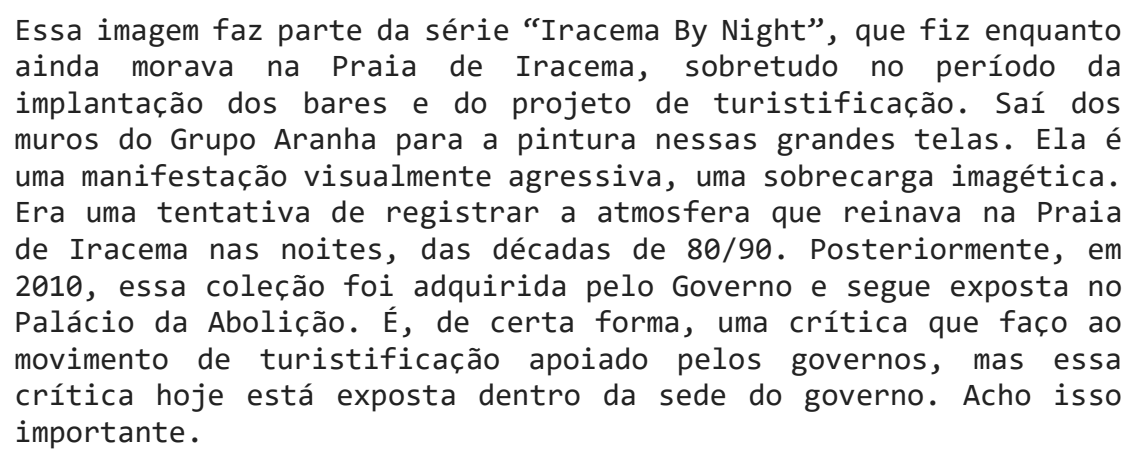

Essa coleção foi ainda apresentada em exposição individual realizada no Museu de Arte Contemporânea na Universidade de São Paulo (MAC USP) em 1996, sob a curadoria de Lisbeth Rebollo. De certo modo, podemos verificar que essa arte-protesto foi bem assimilada pelo campo, por, pelo menos, duas instâncias legitimadoras - a Secretaria de Cultura, em Fortaleza; e o MAC da USP, em São Paulo - conferindo a ela um status de coleção institucionalizada. O diálogo que o artista estabelece com as instituições do campo, dá-se também em outras perspectivas, como aquela materializada na série "A Cor do Crime", produzida em interação com o sistema O Povo de Comunicação:

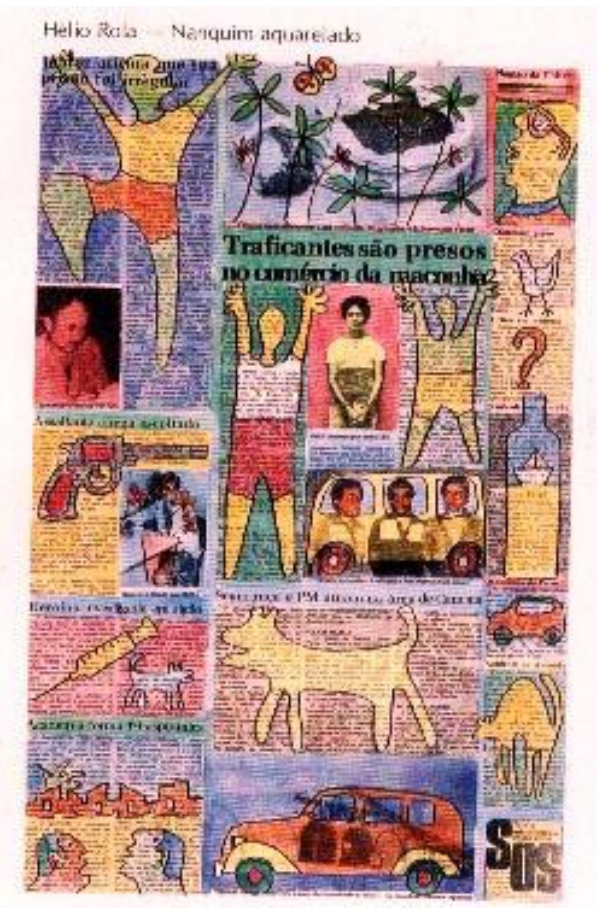

Figura III.5.4: "A cor do crime". Nanquim aquarelado, 1985 Fonte: Acervo do artista Hélio Rôla. 
Era uma interação com o jornal que eu recebia todo dia. Eu recebia esta provocação da página do crime, um belo dia eu resolvi provocar de volta. Mas uma provocação a partir da arte. Interferir na imagem, na diagramação e concepção gráfica do jornal, acabava sendo um pouco disso. Recebia o jornal, selecionava a página policial, desenhava, aquarelava e enviava novamente para a redação do jornal. O Jornal 0 Povo foi receptivo com a ideia e posteriormente fizeram uma exposição com esse material.

Apesar de inesperada, a reação do artista diante dos sucessivos choques - emocionais, estéticos, de valores morais - provocados pelo contato com a forma/conteúdo da página policial do Jornal O Povo, culminou com o estabelecimento de um diálogo produtivo com o veículo de comunicação. A empresa assumiu assim a iniciativa de reunir todas as artes enviadas por Hélio Rôla e promover uma exposição de cunho reflexivo envolvendo problemas sociais, tais como a violência urbana. A esta, o artista responde com recursos oferecidos pela arte.

Queria demonstrar uma sobrecarga imagética e factual na página do
crime. Porque ela dava uma ideia do repertório das ações policiais
cotidianas. Estudando só a página do crime era possível fazer uma
tese. Ela era múltipla. Era uma característica de todos os
jornais. A ideia era dar um realce à pagina do crime, para mostrar
como ela é densa.

Mesmo sendo de certo modo uma insurgência diante do conteúdo veiculado pelo veículo de grande circulação, a exposição teve ainda boa recepção e posteriormente o artista foi convidado a ilustrar semanalmente as publicações do periódico. O que se pode concluir deste episódio é que ações de insurgência e crítica artística não necessariamente significam um desfecho conflituoso, com uma relação hostil entre as partes, mas pode também provocar mudanças qualitativas e intensificar diálogos. A tomada de posição de encaminhar, enviar sua arte protesto, afetando interlocutores desconhecidos, tomou ainda maiores proporções com o engajamento do artista em uma série que encontrou acolhida na chamada Arte Postal.
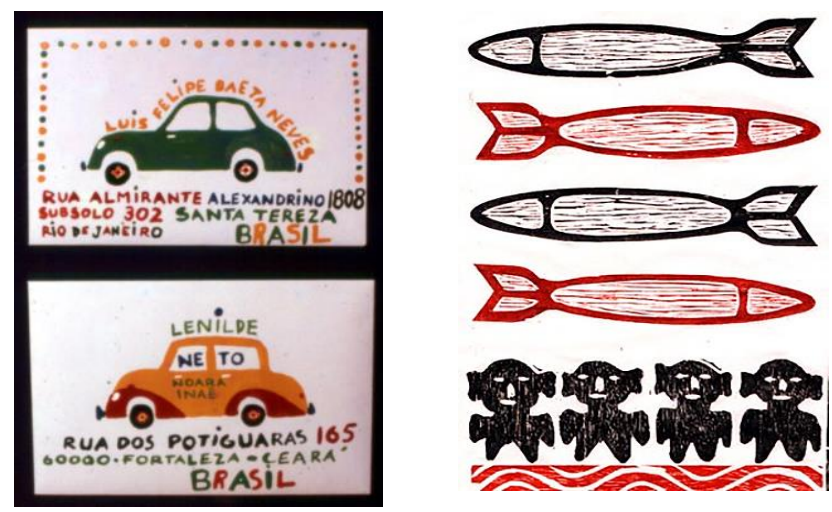

Figura III.5.5: Arte Postal de Hélio Rôla Fonte: Acervo do artista. 
Já na Praia de Iracema, comecei a fazer a arte pelo correio. No Brasil havia uma grande onda de Arte Postal, acabei entrando nessa onda e gostava muito de fazer. Comecei com os desenhos, e depois fui fazendo as xilogravuras copiadas, que, de certa forma era mais cômodo e me permitia um alcance maior. Enviava esse material para cerca de 120 destinatários. No período que estava na França, continuei a fazer esse tipo de trabalho. Era interessante, tinha surpresas no correio. Algumas vezes os funcionários dos correios precisavam recorrer às regras para ver se era possível realizar a postagem do material, que, muitas vezes, fugia do padrão. Segui produzindo durante toda a vida essa arte postal. Nos idos dos anos 2000, migrei para o e-mail, e, atualmente, faço mais pelo Facebook e WhatsApp.

A Arte Postal de Hélio Rôla tinha um propósito claro - interferir e modelar o cotidiano, conforme testemunho do próprio artista. Para tanto, este projeto requeria um trabalho colaborativo que envolveu pelo menos sua esposa, devido ao extenso número de destinatários. Este fator conferia um volume considerável à correspondência, bem como ao fluxo mantido mediante frequência mensal dos envios.

\begin{abstract}
Era um modo de animar, de mudar o tom do cotidiano dos outros e o meu. Desde o pessoal do correio até o destinatário final. Todo feito humano, tem sempre a emoção de mostrar o feito. Fazer e alardear o feito. Na monotonia dos envelopes surge uma coisa feita à mão, interferindo no cotidiano de quem entra em contato.
\end{abstract}

Com o avanço tecnológico, o artista aderiu à comunicação via Internet, iniciando com o envio semanal de e-mails, sempre com uma imagem e reflexões acerca das temáticas de seu interesse, migrando a seguir para as redes sociais, de onde realiza hoje postagens diariamente. Assim, ele passou a manter interlocução mais potente com seus "seguidores ${ }^{176 " ~ a ~ p a r t i r ~ d o s ~}$ comentários e "curtidas ${ }^{177 " ~ q u e ~ e l e s ~ d e i x a m ~ e m ~ s u a ~ p a ́ g i n a ~ n o ~ F a c e b o o k . ~}$

Escolhia um tema, fazia um pequeno desenho e enviava pelo correio. Depois, com a xilogravura, ampliei o alcance porque fazia a xilo, reproduzia em cópias e enviava para uma seleção de destinatários, em torno de 120 pessoas, políticos a amigos e intelectuais. Depois passei a usar também desenhos reproduzidos. Com a chegada do email e Facebook, migrei para as plataformas digitais e sigo fazendo postagens diárias.

O avanço para esse ambiente requereu do artista a apropriação de uma nova ferramenta comunicacional, assim como de um novo modo de operar e compartilhar a sua arte. Especialmente a partir de 2011, momento do ingresso de Hélio Rôla nesta plataforma, é possível reconstituir um percurso, desde seus passos iniciais na rede social em ambiente virtual até o

\footnotetext{
${ }^{176}$ Termo utilizado na Internet para designar pessoas que "seguem" ou acompanham o seu conteúdo, parte da sua rede de contatos nas redes sociais.

${ }^{177}$ Termo utilizado na Internet em referência ao "like", ao ato de curtir um conteúdo postado na rede social.
} 
domínio de uma variedade de modos de conviver e atuar no Facebook. Utilizado como vitrine para exibir suas obras, esse espaço de trocas virtuais passou a ser preenchido por postagens de diversos tipos: mais curtas em forma de poesia e sem imagem; postagens com imagens e texto mais longo; e apenas imagens. Ademais, a relação estabelecida com seus públicos na rede social dá a ele indícios sobre como sua arte é recebida e interpretada, configurando-se como subsídios para uma estratégia de avaliação. A Web Art assim veiculada converte-se em provocação à reflexão por meio da apropriação estética:

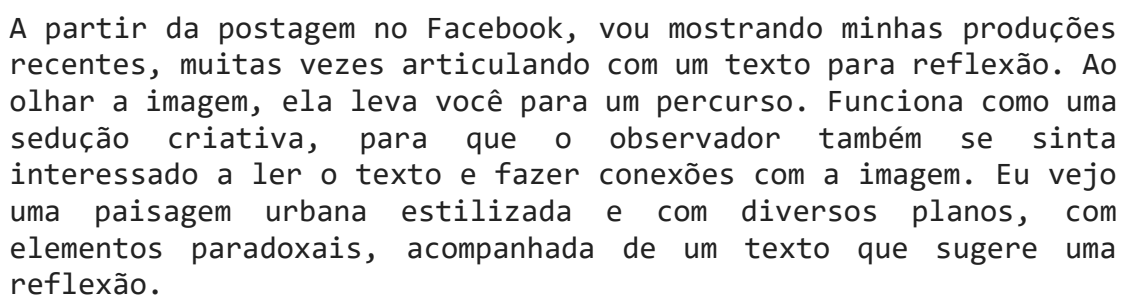
recentes, muitas vezes articulando com um texto para reflexão. Ao olhar a imagem, ela leva você para um percurso. Funciona como uma sedução criativa, para que o observador também se sinta interessado a ler o texto e fazer conexões com a imagem. Eu vejo uma paisagem urbana estilizada e com diversos planos, com elementos paradoxais, acompanhada de um texto que sugere uma reflexão.

O artista retoma também a relevância da paisagem e das discussões sobre a cidade como temática de suas obras:

Desde o começo, minha preocupação é com a paisagem. No começo uma
paisagem que trazia as casinhas com influências do Volpi e outros.
Avancei então para uma construção caótica da cidade, que leva o
observador a transitar nessa paisagem urbana. É uma cidade
inventada. É uma tela pequena, um passatempo que vou produzindo a
partir da temática urbana, que venho fazendo desde o início.
Testando novos materiais, como a caneta posca e uma nova paleta
de cores.

Hélio Rôla ressalta ainda a recorrência da experimentação como forte traço distintivo em sua carreira, seja no tocante a plataformas de produção e exibição, como em relação às técnicas, paletas de cores e temáticas. $A$ imagem abaixo possui especial relevância em seu percurso. Trata-se de um projeto que, posteriormente, foi pintado na fachada do Curso de Ciências Sociais da Universidade Federal do Ceará (UFC), em 1986, na ocasião dos 50 anos do lançamento da bomba atômica em Hiroshima e Nagazaki. Nessa ação, o artista investiu na ligação entre o olhar de um público sensível à produção plástica em meio acadêmico e científico.

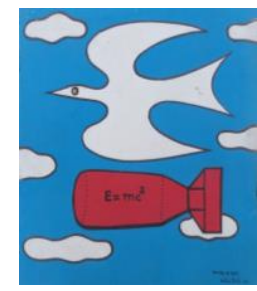

Figura III.5.6: Bomba da Paz, desenho sobre papel de Hélio Rôla, 1985 Fonte: Acervo do artista. 
É uma pseudo pomba da paz. Essa é uma tradução da pomba de Picasso, mas, na dele, a bomba não aparece. Quando chegam as épocas de lamentações sobre conflitos nucleares, surge a Pomba da Paz, surge - Prêmio Lenin da Paz178, que é, no mínimo, contraditório. Essa imagem é uma provocação. Para refletir sobre a relação entre arte e ciência, mas sobretudo para fazer uma provocação sobre a pomba da paz ligada com a bomba atômica. Essa é forma da primeira bomba nuclear, chamada de little boy, a Bomba Atômica. A fórmula do Einstein apresenta uma reflexão sobre a ciência a serviço dos militares, a ciência a serviço da guerra. E a Pomba traz à tona a Pomba da Paz de Picasso. Fiz essa arte enquanto atuava com o Muro didático na Universidade Federal do Ceará. Fiz esse desenho, um projeto para pintar um muro. Foi um artivismo. Eu pintei isso na fachada do prédio das Ciências Sociais da UFC, um lugar de muita visibilidade e espaço de protestos. Foi uma pintura grande, tive apoio dos bombeiros, que me elevaram para conseguir pintar. Isso em 86 .

No momento dessa intervenção, realizada na década de 1980, em pleno processo de redemocratização do regime ditatorial vivido pelo Brasil (1964-1985), Hélio Rôla já era um profissional reconhecido pelo esforço em estreitar laços entre arte e ciência. Para tanto, ele levava para o ambiente acadêmico suas intervenções artísticas, a exemplo desse mural, mas também promovia entrelaçamentos cotidianos como parte da atividade de "sedução pedagógica", realizada em sala de aula. Abaixo, segue outra obra, caracterizada como Digital Art, a qual também objetivava efetivar esta orientação a partir da temática da poluição sonora, abordada insistentemente a partir do início dos anos 2000:

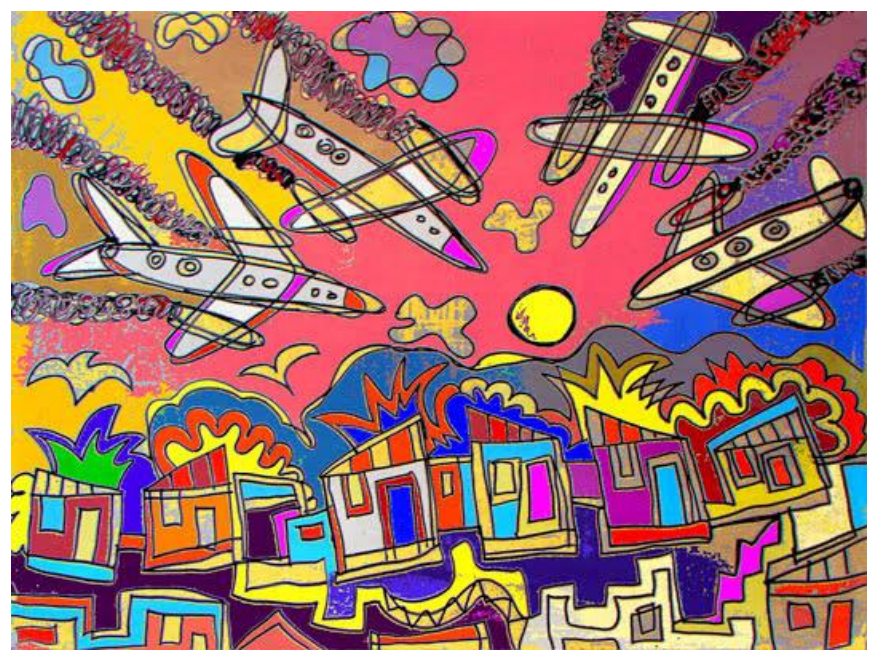

Figura III.5.7: Sem título, arte gráfica digital de Hélio Rôla, 2010 Fonte: Acervo do artista.

\footnotetext{
178 O Prêmio Stalin da Paz, posteriormente renomeado como Prêmio Internacional Lênin para o Fortalecimento da Paz entre os Povos, foi criado em 1949 e extinto em 1991. A premiação ocorria a partir de um comitê internacional indicado pelo Governo soviético, em reconhecimento a indivíduos que tinham trabalhado para o fortalecimento da paz entre os povos. Este prêmio era equivalente ao Prêmio Nobel da Paz. A título de curiosidade, Jorge Amado e Oscar Niemeyer receberam este prêmio.
} 
A importância dessa arte é a sua "desimportância”. Não é uma arte feita visando o lucro ou uma exposição em uma galeria. São como notas de campo. Um rascunho, um apontamento. Uma arte-protesto. Além disso, utilizava essa arte como sedução criativa, trazendo sempre um texto no qual eu comentava sobre o problema da poluição sonora, que era pesada na área da Lagoa Redonda, principalmente fim de tarde e madrugada. Era minha queixa principal, entre os anos de 2007 a 2015.

As ações de Hélio com relação à poluição aeroviária e outros objetos "desimportantes" tiveram diferentes frentes de atuação. O modo como ele desnaturaliza questões evidentes e, portanto, que passam despercebidas ao senso comum e ao poder público, obteve repercussão internacional e acadêmica:

A reiterância na produção dessa arte-protesto sobre a poluição sonora culminou com uma ação civil pública contra a ANAC e a União. Além disso, participei ativamente de debates sobre essa questão. Dessa ação, surgiu também o I Congresso Nacional Multidisciplinar de Ruído Ambiental Urbano e Ruído Aéreo, que foi realizado com apoio do CNPQ e CAPES, para discutir essa questão também no âmbito técnico e acadêmico. Na ocasião do congresso, realizei uma exposição com essas imagens.

A seguir o artista comenta o processo criativo dessas obras, as quais unem diferentes linguagens e técnicas plásticas para a produção de uma arte gráfica digital, culminando na elaboração de uma técnica de produção que prescinde da materialidade em função da adaptação às características comunicacionais das redes sociais e do envio via e-mail.

\footnotetext{
Eu fazia e-mails de protesto, comecei a desenvolver na lousa branca, que me permitia mexer, apagar e refazer. A lousa branca é o risco mais imediato, me permite reparar e seguir produzindo. Diferente da delicadeza do papel e da tela. É também uma matriz descartável e sempre renovável. O desenho na lousa me leva para a fotografia, e, da fotografia, vou para o computador e edito a imagem com infinitas possibilidades, usando o photoshop, que culmina com essa arte gráfica digital. É um desenho rápido, caricatural. Tem um avião na paisagem, casas, carro. Um avião em cima de uma cidade. Não é uma paisagem tranquila, é uma paisagem lancinante. Um céu pegando fogo. Nesse período, entre 2007 e 2015, utilizava essas imagens para postar no Facebook e enviar para uma seleção de destinatários, sempre acompanhado de um texto ou uma reflexão sobre o tema da poluição sonora aeroviária.
}

A arte que encerra esse breve painel, com um recorte da trajetória profissional do artista, revela um sujeito engajado, que se apropria de espaços públicos, concretos e virtuais, aplicando sobre estes recursos estéticos disponíveis para afetar diversos públicos por meio da disseminação de sua arte reflexiva. Encontrar eco no outro a partir da experimentação artística é o desejo expresso de forma recorrente por Hélio Rôla. Porém, mensurar esse eco constitui um recurso da plataforma virtual com a qual o artista trabalha . O desejo de contabilizar, prever, planejar a partir dos índices oferecidos pelas 
redes sociais, revela um artista que se construiu sob a dupla chancela da arte e da ciência, da intuição emocionada e da razão estetizada. Nesse sentido, as redes sociais não só oferecem a possibilidade de interação direta, de distribuição rápida e massiva de obras que expressam inquietação e indignação com problemas de ordem coletiva. De fato, é por meio delas que o artista Hélio Rôla intervém de forma particular, como artista-cientista, sobre os tempos e os espaços pelos quais transitou em seu percurso profissional e de vida.

Neste horizonte, Bourdieu (1995: 16) já ressaltava o poder simbólico dos produtos artísticos: "um poder que pode ser posto a serviço da dominação ou da emancipação, e neste sentido, um campo ideológico com repercussões na vida cotidiana". Guerra (2015) pondera sobre a potência particular que a perspectiva artística tem diante de períodos de crise, uma vez que os artistas estão inseridos em espaços sociais propícios à reflexão e debates que têm por objetivo problematizar questões sociais:

Com efeito, a perspectiva artística da crise social é crucial porque, primeiramente, os artistas participam das reflexões sociais e debates sobre estas circunstâncias históricas; porque os artistas tendem a trabalhar criativamente acerca dessas circunstâncias; porque os artistas têm nas ideias, emoções e comportamentos que despertam nos atores sociais a sua matéria-prima de base para a criação artística; porque as suas obras, artefactos e performances prefiguram e configuram uma representação e um discurso sobre a realidade social. (Guerra, 2015: 8).

Por sua vez, Felshin (1996) entende que a principal estratégia do artivismo se dá na participação efetiva do público por meio da interpretação, sensibilizado pela provocação estética e/ou intelectual, característica potente das Artes Visuais. O percurso de Hélio Rôla nessa direção mobilizou diferentes qualidades de esforços e participação: sua pintura mural, iniciada como ação de combate ao lixo nas ruas, ganhou proporções na vizinhança. Em seguida, passou a integrar no processo de pintura outros coletivos de artistas, os quais se aproximaram para a formação do Grupo Aranha, primeiro coletivo de arte pública de Fortaleza.

A pintura mural de Hélio Rôla também adentrou o universo acadêmico de forma espetacular, com a pintura da Pomba da Paz, na fachada do curso de Ciências Sociais da Universidade Federal do Ceará. Na arte pelo correio, ele mobilizou diferentes grupos sociais, que iam dos representantes do poder público aos segmentos intelectual e artístico, assim como vizinhos e amigos, embora sua intenção original fosse também provocar os sentidos dos funcionários dos Correios atuantes na entrega das suas correspondências 
artísticas. Sua Arte Postal avançou para a Web Arte, que teve início com o envio sistemático de imagens, as quais funcionavam como "sedução criativa" para reflexões em forma de textos, mediante o envio de e-mails e, posteriormente, via redes sociais, como o Facebook, sistema no qual permanece atuante atualmente. Aderindo à arte gráfica no computador, Hélio passou ainda a empreender campanhas em diversas frentes. Talvez a mais singular dentre todas tenha sido a luta contra a poluição sonora aeroviária, na qual sua mobilização a partir da arte teve repercussões duradouras e efetivas, culminando com a participação e envolvimento de entidades que atuam no âmbito jurídico, acadêmico e artístico.

Nesse sentido, Lippard (1984) reforça que o artivismo tem uma perspectiva processual, pois, para além dos mecanismos formais e artísticos, é necessário o planejamento de estratégias de comunicação e distribuição, as quais passam a integrar seu processo criativo, bem como a necessidade de ter clareza em relação aos objetivos da proposta, o modo como atingirá o seu contexto e público, e a sua justificativa. Este é, de certo modo, um trabalho colaborativo com a comunidade com quem está dialogando, conforme reforça Kester (2004):

\begin{abstract}
Partindo das tradições de fazer objetos, esses artistas adotaram uma abordagem performativa baseada em processos. Eles são "provedores de contexto" ao invés de "provedores de conteúdo", nas palavras do artista britânico Peter Dunn, cujo trabalho envolve a orquestração criativa de encontros colaborativos e conversações, bem além dos limites institucionais da galeria ou museu. [...] Essas trocas podem catalisar transformações surpreendentemente poderosas na consciência de seus participantes. As questões levantadas por esses projetos têm claramente uma ressonância cultural e política mais ampla. Kester (2004: 1). ${ }^{179}$.
\end{abstract}

Nesse aspecto cabe ao artista, além da criação dos conteúdos, contribuir para o estabelecimento de contextos que possibilitem a compreensão de suas propostas. O artivismo não se limita a um estilo em particular, mas possui uma intrínseca relação com os seus objetivos, e, devido ao seu caráter multidisciplinar, amplia os meios de comunicação para além dos meios tradicionais da arte. Desse modo, seus projetos incluem estratégias transmidiáticas que possibilitam a criação rizomática em torno do

\footnotetext{
179 No original: Parting from the traditions of object-making, these artists have adopted a performative, process-based approach. They are "context providers" rather than "content providers," in the words of British artist Peter Dunn, whose work involves the creative orchestration of collaborative encounters and conversations well beyond the institutional boundaries of the gallery or museum. [...] these exchanges can catalyze surprisingly powerful transformations in the consciousness of their participants. The questions that are raised by these projects clearly have a broader cultural and political resonance. (Kester, 2004: 1).
} 
mesmo tema, seja a produção de filmes, flyers, eventos, fotografias, performances e instalações (Bennett \& Guerra, 2019).

Fica claro que a arte ativista exige do artista uma disciplina e organização, estratégia e disposição para a interlocução, uma vez que são necessárias ações em diversas frentes para atingir o objetivo da intervenção. Porém, o propósito da prática artivista não se resume ao objetivo de solucionar problemas, mas de, sobretudo, estimular os seus públicos e participantes a refletirem sobre as questões do seu tempo, com o intuito de promover uma mudança ou melhoria sociocultural.

\begin{abstract}
A arte se entrelaça em nossa existência social e nosso presente tecnológico em qualquer época. Os artistas são poetas da vida cotidiana, que, mais do que outros seres humanos, agem com projetos intencionais e, portanto, o que fazem para o curso da história humana não é normalmente trivial. Os artistas vêem ou captam as coerências do presente que a comunidade humana à qual pertence vive, revelando-as de acordo com suas preferências e escolhas de um modo de viver. (Maturana, 2001: 195).
\end{abstract}

Há uma série de autores orientando suas abordagens para a arte ativista. Por isso, sua prática pode ser compreendida a partir da perspectiva de Lacy (1994), que considera o artivismo um gênero de arte pública. Bourriaud (2009) complementa essa formulação ao criar o termo "estética relacional" para falar de trabalhos baseados na comunicação e troca que acontecem inclusive em espaços públicos. Por sua vez, Bhabha (1998) apreende as estéticas contemporâneas com base na perspectiva da "arte e conversação". Kester (2004) formula a ideia de uma arte dialógica, inspirada em Bhaktin, para quem a obra de arte pode ser compreendida como espaço de trocas semelhante ao de uma conversa, sendo o momento de fruição / interação atravessado por diferentes significados, interpretações e pontos de vista.

Nesse sentido, Guerra (2015: 9) lembra que a arte se configura como uma instância produtora de conhecimento "ao representar de forma própria e autônoma a realidade social, interferindo nesta, e ao condicionar e gerar análises e interpretações no seio do conhecimento instituído." Assim, a questão do artivismo reposiciona epistemologicamente a relação arte e sociedade, no sentido de que a arte não é apenas um reflexo ou uma representação da sociedade, mas é sobretudo uma ação criativa, produtora de conhecimento que coloca em relevo problemáticas latentes, invisíveis ou silenciadas, para fomentar então uma reflexão a instaurar a possibilidade de mudança da realidade social. 
O percurso de Hélio Rôla, que articula uma política na arte e uma estética da política, no sentido de mobilizar forças a partir da sua prática artística, tensiona o contexto no qual vive, incitando reflexões e provocando mudanças no seu entorno. Em termos de reconhecimento de sua carreira profissional, o artivismo pode ser percebido como forte presença desde o início de seu percurso como artista, tendo se revelado de forma cada vez mais explícita ao longo do tempo, como um traço que permeia toda a sua obra. $A$ produção artística de Hélio Rôla é suporte para seu engajamento, são os testemunhos de seu tempo. Ao ser perguntado sobre qual seria a marca expressiva de sua obra, o artista responde: "É colocar minha arte a meu serviço. A questão não é o que você pode fazer por sua arte, é o que a sua arte pode fazer por você". Suas obras com teor artivista revelam, acima de tudo, a paisagem interna do artista, sua inquietação frente às transformações que ele vivencia. Para Hélio Rôla, o importante é estar em permanente diálogo com o seu entorno. Ao ser questionado de por que precisava fazer todo dia uma postagem no Facebook, ele respondeu: "Pra intervir no tom do cotidiano". É possível conectar essa fala do artista com a ideia de Picasso para quem "A pintura não foi feita para enfeitar paredes. A pintura é uma arma, é a defesa contra o inimigo". Se para Bourdieu é a sociologia, para Hélio Rôla a arte parece funcionar como um esporte de combate.

\section{Referências Bibliográficas}

Bennett, A. \& Guerra, P. (2019) (Eds.). DIY cultures and underground music scenes. Abingdon/New York: Routledge.

Bourdieu, P. \& Haacke, H. (1995). Livre-troca: diálogos entre ciência e arte. Rio de Janeiro: Bertrand Brasil.

Bourriaud, N. (2009). Estética relacional. São Paulo: Martins.

Felshin, N. (1996). But is it art? The spirit of art as activism. Seattle: Bay Press.

Guerra, P. (2016). A canção ainda é uma arma: ensaio sobre as identidades na sociedade portuguesa em tempos de crise. In Nascimento, Francisco de Assis de Sousa; Silva, Jaison Castro; Ferreira Da Silva, Ronyere (Orgs.). História e Arte: Teatro, cinema, literatura. Teresina: EDUFPI.

Zembylas, T. (2014). Artistic Practices: social interactions and cultural dynamics. Londres: Routledge.

Kester, G. H. (2004). Conversation pieces: Community + communication in modern art. Berkeley. California: University of California.

Lacy, S. (1994). Mapping the terrain. New Genre: Bay Press. 
Longoni, A. (2009). Activismo artístico en la última década en Argentina: algunas acciones em torno a la segunda desaparición de Jorge Julio López. Errata \# - Revista de Artes visuales: El lugar del arte en lo político, 0(0), pp. 16-35.

Lippard, L. R. (1984). Trojan Horses: Activist art and power. In Wallis, Brian. Art after modernism: rethinking representation. New York: The New Museum of Contemporary Art.

Maturana, H., \& Varela, F. (1997). De máquinas e seres vivos - autopoiese: a organização do vivo. Porto Alegre: Artes Médicas.

Mourão, R. (2015). Performances artivistas: incorporação duma estética de dissensão numa ética de resistência. Cadernos de Arte e Antropologia, v.4, n.2, pp.12-17.

Rolim, H. (2015). Pintura sensorial, pintura conceitual: Herbet Rolim escreve sobre o Grupo Aranha, da chamada Geração 80 e um marco da história das artes no Ceará. Diário do Nordeste.

Raposo, P. (2015). Artivismo: articulando dissidências, criando insurgências. Cadernos de Arte e Antropologia, v. 4, n.2, pp.20-25. 